\title{
QUALIDADE QUÍMICA E FÍSICA DE BERINJELAS SUBMETIDAS A DIFERENTES TRATAMENTOS PÓS-COLHEITA
}

\author{
Celso L. MORETTI'; Livia L. O. PINELI
}

\begin{abstract}
RESUMO
O presente trabalho foi conduzido com o objetivo de avaliar a qualidade química e física de berinjelas submetidas a diferentes tratamentos pós-colheita. Berinjelas (Solanum melongena L.), cultivar Ciça, foram colhidas em campos de produção comercial em Brasília-DF e submetidas aos seguintes tratamentos: atmosfera modificada; $\mathrm{CaCl}_{2}(2 \%)+$ atmosfera modificada; aplicação de 1-MCP (500nL.L ); aplicação de 1-MCP (500nL.L ) + $\mathrm{CaCl}_{2}(2 \%)$; e controle. Após os tratamentos, os frutos foram armazenados por 10 dias $\left(12 \pm 1^{\circ} \mathrm{C} /\right.$ UR $\left.85-90 \%\right)$ e avaliados a cada dois dias para perda de massa, firmeza, coloração externa e teor de sólidos solúveis totais ( $\left.{ }^{\circ} \mathrm{Brix}\right)$. Observou-se que ao final do experimento os frutos do tratamento controle apresentavam perda de massa ao redor de $14 \%$. No décimo dia de armazenamento os frutos tratados com cloreto de cálcio associado à atmosfera modificada e aqueles armazenados sob atmosfera modificada apresentavam firmeza 2,5 vezes maior do que o tratamento controle. Ao final do experimento os frutos armazenados sob atmosfera modificada possuiam brilho, que era cerca de $20 \%$ maior do que o dos frutos do tratamento controle. Berinjelas do tratamento controle possuíam Brix cerca de $20 \%$ maior do que dos frutos armazenados sob atmosfera modificada ao final do experimento.
\end{abstract}

Palavras-chave: armazenamento; atmosfera modificada; cloreto de cálcio; 1-metilciclopropeno; vida-de-prateleira.

\section{SUMMARY}

CHEMICAL AND PHYSICAL QUALITY OF EGGPLANT FRUITS SUBMITTED TO DIFFERENT POSTHARVEST TREATMENTS. The present work was carried out aiming to evaluate chemical and physical characteristics of eggplant fruits submitted to different postharvest treatments. Eggplant fruits (Solanum melongena L.) were harvested in commercial fields in Brasilia, DF. After harvesting the, fruits were graded for size and diameter and treated as follows: modified atmosphere; $\mathrm{CaCl}_{2}(2 \%)$ dipping + modified atmosphere; 1-MCP (500nL.L ) ; 1-MCP (500nL.L ) $+\mathrm{CaCl}_{2}(2 \%)$ dipping; and control. Fruits were then stored for 10 days at $12 \pm 1^{\circ} \mathrm{C}$, relative humidity ranging from 85 to $90 \%$, and analyzed every two days for mass loss, firmness, external color (brightness) and total soluble solids content. It was observed that mass loss increased during storage. At the end of the storage period control fruits had a mass loss of $14 \%$, and fruits treated with calcium chloride, with or without the association of modified atmosphere, were 2.5 times firmer than control fruits. For brightness, fruits stored under modified atmosphere had $L^{*}$ values that were $20 \%$ higher than control fruits at the tenth day of storage. When total soluble solids were evaluated, it was verified that, at the end of the storage period, control fruits had $20 \%$ more soluble solids than fruits stored under modified atmosphere.

Keywords: $\mathrm{CaCl}_{2}$; eggplant; storage; shelf-life; 1-methylcyclopropene; modified atmosphere.

\section{1 - INTRODUÇÃO}

A berinjela (Solanum melongena L.) sempre foi considerada hortaliça de importância secundária, porém, dado o crescente interesse da população em consumir produtos de origem vegetal, com baixas calorias, seu volume comercializado vem aumentando continuamente $[3,32$, 40]. A berinjela é uma solanácea rica em vitaminas A, B1, riboflavina, niacina e ácido ascórbico [12], sendo-lhe popularmente atribuído efeito nutracêutico na redução de risco de doenças coronarianas. Alguns estudos têm confirmado essa propriedade, conforme observado por JORGE et al. [23] que, entre outros resultados, verificaram a redução do colesterol total e tecidual, das LDL plasmáticas, dos triglicérides e da peroxidação lipídica em coelhos hipercolesterolêmicos, tratados com suco de berinjela.

Recebido para publicação em 23/03/2004. Aceito para publicação em 04/05/2005(001313).

Laboratório de Pós-colheita, EMBRAPA Hortaliças. CEP: 70359-970, Brasília-DF.

Departamento de Nutrição, Universidade de Brasília. CEP: 70910900, Brasilia-DF.

A quem a correspondência deve ser enviada.
No Brasil, os frutos de berinjela são geralmente comercializados a granel e sem o uso de refrigeração, comprometendo a sua qualidade final. A perda do valor comercial e nutritivo é observada em poucos dias pela ocorrência de murchamento e pelo aspecto esponjoso e sem brilho dos frutos [15]. As berinjelas são sensiveis à injúria pelo frio, especificamente em temperaturas inferiores a $10^{\circ} \mathrm{C}$, apresentando, de acordo com o tempo de exposição, uma série de sintomas que depreciam sua qualidade comercial [38]. O aparecimento de depressões superficiais ("surface pitting"), bronzeamento da casca e escurecimento da polpa e das sementes são os principais sintomas da injúria pelo frio nesta hortaliça [27]. Em trabalhos conduzidos com berinjelas da cultivar Ciça, HENZ \& SILVA [15] concluíram que a temperatura de armazenamento ideal é de $12^{\circ} \mathrm{C}$, sendo que nestas condições os frutos apresentaram praticamente inexistência de sintomas de dano pelo frio.

Dentre diversas tecnologias utilizadas para extensão da vida-de-prateleira e manutenção da qualidade de frutas e hortaliças, a aplicação do 1-metilcilcopropeno (1MCP), um antagonista de ação do etileno, bem como a de cálcio (na forma de $\mathrm{CaCl}_{2}$ ) visando o aumento da firmeza dos frutos, e a utilização de filmes plásticos (embalagem sob atmosfera modificada) têm sido amplamente estuda- 
das, notadamente em associação com o uso de baixas temperaturas $[8,22,34]$. Os efeitos da aplicação de 1-MCP em algumas frutas e hortaliças têm sido observados em diversos estudos [2], sendo os mais importantes o retardamento do amadurecimento e da senescência, a manutenção da firmeza, a redução da degradação de polímeros da parede celular e a diminuição da taxa respiratória, da produção de etileno, da perda de massa, da injúria pelo frio, da degradação da clorofila e do amido e do escurecimento da polpa, entre outros. MORETTI et al. [30] verificaram que tomates tratados com 1000nL.L de 1-MCP possuíam firmeza $88 \%$ maior do que frutos do tratamento controle após dezessete dias de armazenamento. A relação $a^{*} / b^{*}$, um indicativo da coloração da casca, foi $38 \%$ menor em tomates tratados com 1000nL.L quando comparados com frutos do tratamento controle ao final do experimento. Os autores verificaram que a aplicação pós-colheita de 1-MCP foi um método eficiente em retardar o amadurecimento de tomates. Em outra série de estudos, MORETTI et al. [31] verificaram que a aplicação pós-colheita do 1-MCP (1000nL.L ) retardou a evolução de gás carbônico e etileno por períodos variando entre 10 e 12 dias quando comparou-se a testemunha e frutos tratados por 3, 6 e 12 horas. Pelos resultados observados em outras culturas, no que diz respeito ao retardamento da degradação de clorofila, acredita-se que o 1-MCP possa ser aplicado em berinjelas com o intuito de retardar a perda da cor verde do cálice dos frutos.

O cálcio tem-se mostrado efetivo na redução da degradação de clorofila e de algumas proteínas e na inibição da senescência do tecido vegetal [37]. Ligações cruzadas de polímeros pécticos, mediadas pelo cálcio, têm sido citadas como possivel mecanismo para controle da perda de firmeza em diferentes frutos [1, 13, 41]. Entretanto, há evidências crescentes de que o mecanismo molecular da ação do cálcio é, em parte, em nível de integridade de membrana [10, 28, 33].

A modificação da atmosfera circundante ao produto, denominada atmosfera modificada [AM], pode ser usada com o objetivo de controlar o metabolismo respiratório. O uso de baixas concentrações de $\mathrm{O}$ ( 1 a $5 \%)$ e altas concentrações de $\mathrm{CO}_{\text {, }}\left(5\right.$ a 10\%, balanço com $\mathrm{N}_{2}$ ), em associação com baixas temperaturas de armazenamento, é proposto por muitos pesquisadores como condição ótima para manutenção das qualidades sensorial e microbiológica de frutas e hortaliças frescas [20, 24, 25]. A combinação das diferentes taxas de permeabilidade aos gases e vapores dos filmes poliméricos com a taxa respiratória do produto embalado leva a uma atmosfera modificada de equilíbrio [6], que também é função das condições de armazenamento [16].

Apesar de sua importância estratégica em diversas regiões produtoras de hortaliças no país, a literatura consultada é deficiente no que diz respeito a estudos de diferentes tecnologias de pós-colheita visando a extensão da vida-de-prateleira de berinjelas. Tais informações são extremamente relevantes para empresas que vislumbram a possibilidade de exportar essa hortaliça para países do Mercosul.

O objetivo deste trabalho foi avaliar a qualidade química e física de berinjelas submetidas a diferentes tratamentos pós-colheita, visando a extensão da vida-deprateleira do produto.

\section{2 - MATERIAL E MÉTODOS}

\section{1 - Seleção do material vegetal}

Frutos de berinjela (Solanum melongena L.), cultivar Ciça, foram colhidos no ponto ótimo de maturidade hortícola, em campos de produção comercial do Distrito Federal. Após a colheita, os frutos foram transportados para o Laboratório de Pós-Colheita da EMBRAPA Hortaliças, selecionados quanto à presença de danos externos e classificados por tamanho $(20 \pm 2 \mathrm{~cm})$ e diâmetro $(5 \pm 1 \mathrm{~cm})$. Frutos fora das especificações descritas foram descartados.

\section{2 - Resfriamento rápido}

Após a seleção, os frutos foram submetidos ao resfriamento rápido por imersão em água gelada até a temperatura de $10^{\circ} \mathrm{C}$ [5], com exceção dos frutos que foram tratados com 1-metilciclopropeno (1-MCP), que só foram resfriados após o tratamento com o gás. O tratamento com 1-MCP foi feito em câmara hermética dotada de mini-ventiladores, a $20^{\circ} \mathrm{C}$ por 12 horas.

\section{3 - Tratamentos}

Os frutos foram submetidos aos seguintes tratamentos: embalagem em filme de polietileno de baixa densidade com espessura de $18 \mu \mathrm{m}$; imersão por 5 minutos em solução de cloreto de cálcio ( $2 \%$ em água; $\mathrm{p} / \mathrm{p}$ ), seguida de embalagem em filme de polietileno de baixa densidade com espessura de $18 \mu \mathrm{m}$; aplicação de 500nL.L de 1-MCP; combinação do tratamento com cloreto de cálcio ( $2 \%$ em água; $p / p)$ por imersão por 5 minutos com a aplicação de 1-MCP(500nL.L'); e controle.

Os frutos de berinjela foram armazenados durante um período de 10 dias sob refrigeração $\left(12 \pm 1^{\circ} \mathrm{C}\right.$ e umidade relativa variando entre 85 e $90 \%$ ).

\section{4 - Análises físicas e químicas}

A cada dois dias os frutos foram avaliados para as seguintes variáveis químicas e fisicas: perda de massa, firmeza, coloração externa (brilho L) e teor de sólidos solúveis totais. A perda de massa foi determinada pela diferença, em porcentagem, entre a massa inicial e a massa verificada ao final de cada periodo de armazenamento. Os frutos foram pesados em balança analítica (Marte M 250, São Paulo, Brasil). A firmeza foi determinada por meio de um penetrômetro a gás, segundo metodologia descrita por CALBO \& MORETTI [4], com resultados expressos em Newtons. A coloração foi avaliada com um colorímetro Minolta (modelo CR 200 b, Tokyo, Japão) no sistema triaxial $\mathrm{L}^{*} \mathrm{a}^{*} \mathrm{~b}^{*}$. O teor de sólidos solúveis totais foi 
medido em refratômetro digital (Abbe 112, Tokyo, Japão) e expresso em ${ }^{\circ}$ Brix.

\section{5 - Delineamento estatístico}

A análise estatística foi conduzida utilizando-se delineamento inteiramente casualizado com 5 tratamentos e 4 repetições (10 frutos por parcela). Os dados foram submetidos à análise de variância e o teste de diferença mínima significativa foi conduzido. Diferenças entre dois tratamentos quaisquer maiores do que a soma de dois desvios-padrão foram sempre consideradas significativas $(\mathrm{P} \leq 0,05)$.

\section{3 - RESULTADOS E DISCUSSãO}

\section{1 - Perda de massa}

Observou-se que os frutos apresentaram perda de massa crescente ao longo do período de armazenamento. Os frutos tratados com 1-MCP e aqueles provenientes do tratamento controle apresentaram perda de massa similar ao longo do período experimental, sendo que, no décimo dia de armazenamento, os frutos do tratamento controle apresentavam perda ao redor de $14 \%$ sendo, todavia, inferior à perda do tratamento com 1-MCP (Figura 1).

Por outro lado, os frutos embalados com filme plástico (sob atmosfera modificada), com ou sem associação ao cloreto de cálcio, apresentaram a menor perda de massa entre os cinco tratamentos. Ao final do experimento, ambos tratamentos apresentavam perda de massa inferior a 3\% (Figura 1).

Os resultados obtidos no presente experimento estão de acordo com os obtidos por KAYNAS et al. [26]. Esses pesquisadores verificaram que berinjelas armazenadas a $12^{\circ} \mathrm{C}$ por 42 dias, em embalagens com atmosfera modificada ou controlada, tiveram perdas de massa significativamente menores do que berinjelas sem embala-

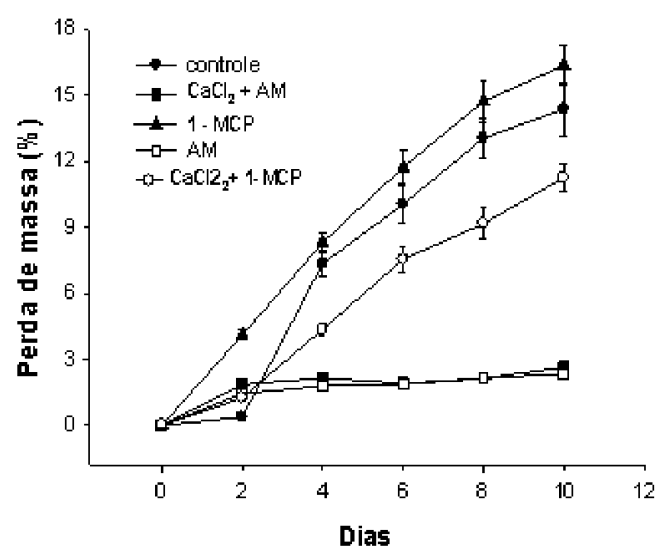

FIGURA 1 - Perda de massa (\%) de berinjelas submetidas a diferentes tratamentos pós-colheita e armazenadas sob refrigeração $\left(12 \pm 1^{\circ} \mathrm{C} / \mathrm{UR}\right.$ 85-90\%) em câmara fria. EMBRAPA Hortaliças, Brasilia, DF, 2001 gem. FALLIK et al. [8] observaram que a perda de massa e a firmeza de frutos eram significativamente menores em berinjelas embaladas em embalagens de polietileno de baixa densidade do que em berinjelas sem embalagem, armazenadas a $6,8 \mathrm{e} 12^{\circ} \mathrm{C}$.

Diversos trabalhos relatam o efeito do 1-MCP na diminuição da perda de massa em diferentes produtos [9, $17,21,29,35,36]$. Segundo BLAKENSHIP \& DOLE [2], a aplicação de 1-MCP em baixas temperaturas não é efetiva para algumas hortaliças e frutas. Uma relação foi encontrada entre tratamento e tempo de aplicação. Maçãs a $3^{\circ} \mathrm{C}$ requereram 9 horas de tratamento a uma dada concentração de 1-MCP, enquanto apenas 6 horas eram necessárias, em temperaturas maiores, para retardar o amadurecimento [7]. Deve-se frisar que, todavia, a aplicação do 1-MCP em berinjelas na dosagem de 500nL.L" não foi suficiente para retardar a perda de massa dos frutos.

Adicionalmente ao observado para perda de massa, verificou-se que a aplicação do 1-MCP não contribuiu para a retenção da coloração verde do cálice das berinjelas (dados não apresentados). A retenção da cor verde do cálice é considerada por produtores e consumidores como uma característica de qualidade desejável de berinjelas.

\section{2 - Firmeza}

Verificou-se que, de maneira geral, os frutos apresentaram tendência de redução da firmeza ao longo do período de armazenamento. Ao final do experimento, as berinjelas do tratamento controle apresentavam a menor firmeza entre os tratamentos estudados (Figura 2).

No décimo dia de armazenamento, os frutos armazenados sob atmosfera modificada, com ou sem aplicação de cálcio apresentavam firmeza significativamente maior do que o tratamento controle, sendo ao redor de 2,5 vezes maior (Figura 2), demonstrando que a adição de cálcio às berinjelas, por imersão, não contribuiu de maneira significativa para a retenção da firmeza.

A redução da concentração de $\mathrm{O}_{2}$ e a elevação da tensão de $\mathrm{CO}_{2}$ diminui a taxa metabólica e a respiração dos frutos, reduzindo a produção e a ação fisiológica do etileno, que dependem de concentrações altas de $\mathrm{O}_{2}$ e baixas de $\mathrm{CO}_{\text {[ }}$ [39]. Essa redução afeta a decomposição da lamela média da parede celular, determinando suas propriedades texturais e de consumo [18]. A perda de firmeza, ocasionada por mudanças na atividade de enzimas presentes nas células que, juntamente com a perda de água, contribui para as mudanças de textura [11], tem como causas sugeridas a degradação da protopectina primária, o aumento da pectina solúvel e a perda de açúcares não-celulósicos, presentes durante o amadurecimento dos frutos [14]. Do exposto, sugere-se que os frutos armazenados sob atmosfera modificada, com ou sem aplicação de cálcio, mantiveram firmeza maior que os demais tratamentos em função do metabolismo destes frutos ter sido reduzido pela diminuição das concentrações de $\mathrm{O}_{2}$ e 


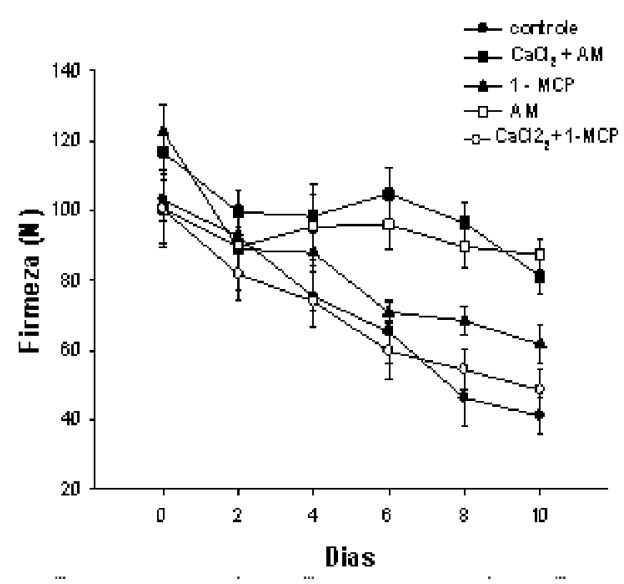

FIGURA 2 - Firmeza (N) de berinjelas submetidas a diferentes tratamentos pós-colheita e armazenadas sob refrigeração $\left(12 \pm 1^{\circ} \mathrm{C} / \mathrm{UR}\right.$ 85-90\%) em câmara fria. EMBRAPA Hortaliças, Brasília, DF, 2001.

elevação de $\mathrm{CO}_{2}$ no ambiente de armazenamento ocasionados pela modificação de atmosfera.

\section{3 - Brilho (L)}

Observou-se que, de maneira geral, os frutos de berinjela tenderam a apresentar uma redução do brilho durante o armazenamento refrigerado, independentemente do tratamento sofrido (Figura 3).

Constatou-se que os frutos embalados em filme de PEBD, com ou sem a aplicação de cálcio, apresentaram, de maneira consistente, maior brilho do que os demais frutos durante o período experimental (Figura 3). Os frutos armazenados sob atmosfera modificada apresentaram brilho significativamente superior aos demais tratamentos. Ao final do experimento, frutos armazenados sob atmosfera modificada apresentavam brilho que era cerca de $20 \%$ maior do que o brilho dos frutos do tratamento controle (Figura 3).

JHA \& MATSUOKA [22] relatam que a medida da reflectância especular da superficie de berinjelas poderia auxiliar na determinação e desenvolvimento de técnicas não-destrutivas para avaliação de sua qualidade e frescor. A reflectância especular é uma função da reflectância espectral e é dependente da fonte e da intensidade de luz coincidente, que é um dos principais atributos que influenciam a percepção de qualidade de frutas e hortaliças. Para a maioria dos materiais, a reflectância especular é um atributo perceptível das superficies, relacionado ao grau com o qual ele estimula um espelho perfeito na sua capacidade de refletir a luz incidente [19].

Para WARD \& NUSSINOVITCH [42], a perda de massa afeta a reflectância especular, o que foi confirmado por JHA \& MATSUOKA [22], que observou em seu estudo que a reflectância especular da superficie de berinjelas de-

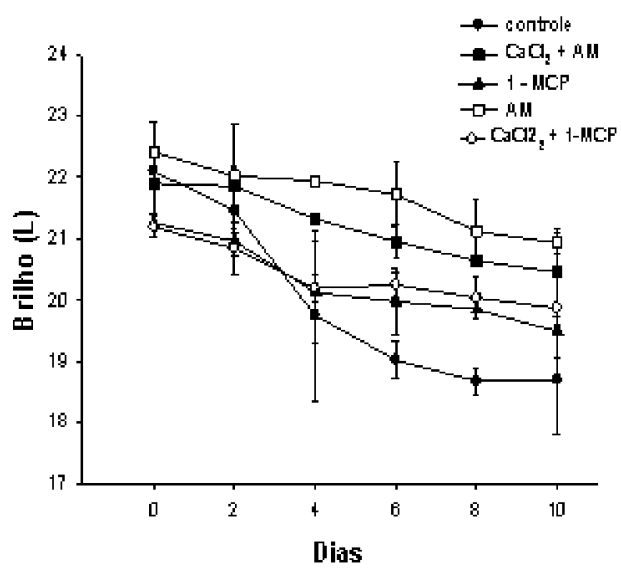

FIGURA 3 - Brilho de berinjelas submetidas a diferentes tratamentos pós-colheita e armazenadas sob refrigeração $\left(12 \pm 1^{\circ} \mathrm{C} / \mathrm{UR} 85-90 \%\right)$ em câmara fria. EMBRAPA Hortaliças, Brasília, DF, 2001

cresceu linearmente com o peso das berinjelas. De maneira similar ao verificado por estes pesquisadores, verificou-se no presente trabalho que as berinjelas que tiveram a maior perda de massa foram também as que tiveram o brilho inferior, quando comparado com os frutos que perderam menos massa. Tais resultados confirmam a tese de JHA \& MATSUOKA [22] de que a perda de massa afeta significativamente a reflectância especular.

\section{4 - Teor de sólidos solúveis totais ( Brix)}

Observou-se que o teor de sólidos solúveis totais dos frutos de berinjela variou entre 4,2 e $5,4^{\circ} \mathrm{Brix}$ e apresentando tendência de crescimento para os frutos que não estavam armazenados sob atmosfera modificada (Figura 4).

Verificou-se que os frutos que apresentaram menor perda de água, isto é, frutos dos tratamentos armazenados sob atmosfera modificada, com ou sem cálcio (Figura 1), eram os que possuíam o menor teor de sólidos solúveis ao final do periodo experimental (Figura 4). A perda de água contribuiu para a concentração dos sólidos solúveis totais nos frutos. Ao final do experimento o brix das berinjelas do tratamento controle era cerca de $20 \%$ maior do que dos frutos armazenados sob atmosfera modificada (Figura 4).

Os resultados encontrados no presente experimento estão em consonância com os observados por KAYNAS et al. [26], que verificaram que houve aumento nos teores de açúcares solúveis e diminuição nos teores de amido em berinjelas armazenadas sem embalagem plástica em comparação com frutos armazenados sob atmosfera modificada, demonstrando que além da perda de água contribuir para a concentração dos sólidos solúveis, o estresse causado aumenta o metabolismo do amido, que é hidrolisado em compostos de menor peso molecular, co- 


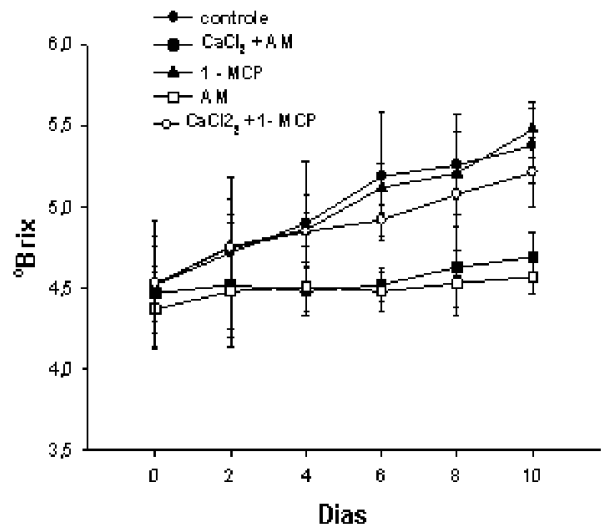

FIGURA 4 - Teor de sólidos solúveis totais (Brix) de berinjelas submetidas a diferentes tratamentos pós-colheita e armazenadas sob refrigeração $\left(12 \pm 1^{\circ} \mathrm{C} / \mathrm{UR} 85-90 \%\right)$ em câmara fria. EMBRAPA Hortaliças, Brasília, DF, 2001

mo os açúcares solúveis, redundando no aumento do teor de sólidos solúveis totais.

\section{4 - CONCLUSÕES}

Com base nos resultados obtidos, pôde-se concluir que as berinjelas embaladas com filme de polietileno de baixa densidade (espessura de $18 \mu \mathrm{m}$ ), com ou sem aplicação de cálcio, apresentaram menor perda de massa, maior firmeza e melhor brilho que os demais tratamentos. Tais características possibilitaram que os frutos manuseados nestas condições mantivessem sua qualidade visual por até 10 dias, intervalo de tempo suficiente para propiciar a exportação destes frutos para países do Mercosul.

\section{5 -REFERÊNCIAS BIBLIOGRÁFICAS}

[1] BANGERTH, F. Calcium related physiological disorders of plants. Annual Review of Phytopathology, v.17, p.97-122, 1979.

[2] BLANKENSHIP, S. M.; DOLE, J. M. 1 Methylcyclopropene: a Review. Postharvest Biology and Technology, 28, p. 1-25, 2003.

[3] BOletim MENSAl CEAGESP. São Paulo, CEAGESP, n.12, dez., 1994.

[4] CALBO, A. G.; MORETTI, C. L. Embrapa Hortaliças CNPH . Brasilia, 2003. Disponivel em www.cnph.embrapa.br/laborato/pos_colheita/ penetrometro.htm . Acesso em: 12 set. 2003.

[5] CORTEZ, L. A. B.; VIGNEAUlT, C.; CASTRO, L. R. Método de resfriamento rápido por água gelada. In: CORTEZ, L. A. B., HONORIO, S. L., MORETTI, C. L. Resfriamento de Frutas e Hortaliças. Brasília: Embrapa Informação Tecnológica, p. 273-280, 2002.

[6] DAY, B. D. F. High oxygen modified atmosphere packaging for fresh prepared produce. Postharvest News and Information, v. 7, p. 31-34, 1996.
[7] DELL, J. R.; MURR, D.P.; PORTEOUS, M.D.; RUPASINGHE, H.P.V. Influence of temperature and duration of 1-methylcyclopropene [1-MCP] treatment on apple quality. Postharvest Biology and Technology, v. 24, p. 349-353, 2002

[8] FALLIK, E.; NAOMI, T.G.; SHOSHANA, G.; DAVIDSON, $\mathrm{H}$. Prolonged low temperature storage of eggplants in polyethylene bags. Postharvest Biology and Technology, v. 5, p. 85-89, 1995.

[9] FENG, X.; APELBAUM, A.; SISLER, E.C.; GOREN, R. Control of ethylene responses in avocado fruit with 1- methylciclopropene. Postharvest Biology and Technology, v.20, p. 143-150, 2000.

[10] FERGUSON, I. B. Calcium in plant senescence and fruit ripening. Plant Cell Environment, v. 7, p. 477-489, 1984.

[11] FISCHER, M.; AMADO, R. Changes in the pectic substances of apples during development and postharvest ripening. Part 1: Analysis of the alcoholinsoluble residue. Carbohydrate Polymers Great Britain, v. 25, p.161-166, 1994.

[12] FLICK, G. J.; BURNETTE, F. S.; AUNG, L. H.; ORY, R. L.; ANGELO, A. J. Chemical composition and biochemical properties of mirlitons (Sechium edue) and purple, green and white eggplants (Solanum melongena). Journal of Agricultural and Food Chemistry, v. 26, p. 1000-1005, 1978.

[13] FRY, S.C. Cross-linking of matrix polymers in the growing cell walls of Angiosperms. Annual Review of Plant Physiology, v. 37, p. 165-186, 1986.

[14] GROSS, K. C.; SAMS, C. E. Changes in cell wall neutral sugar composition during fruit ripening: a species survey. Phytochemistry, Elmsford, v.23 ,n. 11, p. 2457 2461, 1984.

[15] HENZ, G. P.; SIlvA, C. Conservação de frutos de berinjela cv. Ciça através de refrigeração e embalagem. Pesquisa Agropecuária Brasileira, v. 30 , n.2, p. 157$162,1995$.

[16] HERTOG, M. L.; TIJSKENS, L. M. M. Modeling modified atmosphere packaging of perishable produce: keeping quality at dynamic conditions. Acta Alimentaria, v. 27, p. 53-62, 1998.

[17] HOFMAN, P. J.; JOBIN-DÉCOR, M.; MEIBURG, G. F; MACNISH, A. J., JOYCE, D. C. Ripening and quality responses of avocado, custard apple, mango and papaya fruit to 1-methylcyclopropene. Australian Journal of Experimental Agriculture, v. 41, p. 567-572, 2001.

[18] HUBER, D. J. The role of cell wall hydrolases in fruit softening. Horticultural Review, v. 5, p.169-219, 1983.

[19] HUNTER, R. S. Gloss evaluation of materials. ASTM Bulletin, v.186, p. 48-55, 1952.

[20] JACXSENS, L; DEVLIEGHERE, F; DE RUDDER, T.; DEBEVERE, J. Designing equilibrium modified atmosphere packages for fresh-cut vegetables subjected to changes in temperature. Lebensmittel-Wissenschaft und-Technologie, v. 33, p. 178-187, 2000.

[21] JEONG, J.; HUBER, D. J., SARGENT, S. A. Influence of 1methylcyclopropene (1-MCP) on ripening and cell-wall matrix polysaccharides of avocado (Persea Americana) 
fruit. Postharvest Biology and Technology, v. 25, p. 241-364, 2002.

[22] JHA, S. N.; MATSUOKA, T. Non-destructive techniques for quality evaluation of intact fruits and vegetables a review. Food Science and Technology Research, v. 6, n. 4, p. 284-285, 2002.

[23] JORGE, P. A. R.; NEYRA, L. C.; OSAKI, R. M; ALMEIDA, E.; BRAGAGNOLO, N. Efeito da berinjela sobre os Lipides plasmáticos, a peroxidação lipídica e a reversão da disfunção endotelial na hipercolesterolemia experimental. Arquivos Brasileiros de Cardiologia, v. 70, n. 2, p. 87-91,1998.

[24] KADER, A. A. Prevention of ripening in fruits by use of controlled atmospheres. Food Technology, v.34, p. 5054,1980 .

[25] KADER, A. A.; ZAGORY, D.; KERBEL, E. L. Modified atmosphere packaging of fruits and vegetables. Critical Reviews in Food Science and Nutrition, v. 28, p. 1-30. 1989.

[26] KAYNAS, K.; ÖZELKöK, S.; SüMELI, N.; ABAK, K. Controlled and modified atmosphere storage of eggplant [SOLANUM MELONGENA L.] fruits . Acta Horticulturae [ISHS], v. 412, p. 143-151,1995.

[27] Kluge, R. A.; ANTONini, A. C. C.; RoBles, W. G. R.; NETO, J. T.; JACOMINO, A. P.; FILHO, J. A. S. Avaliação de cultivares de berinjela em armazenamento refrigerado. Scientia Agricola, v. 56, n.4, p. 1045-1050, 1999.

[28] LESTER, G. Calcium alters senescence rate of postharvest muskmelon fruit disks. Postharvest Biology and Technology, v. 7, p. 91-96, 1996.

[29] MACNISH, A. J.; SIMONS, D. H.; JOYCE, D. C.; FARAGHER, J. D.; HOFMAN, P. J. Responses of native australian cut flowers to treatment with 1Metilcyclopropene and ethylene. Hortscience, v. 35, p. 254-255, 1999.

[30] MORETTI, C. L.; ARAUJO, A. L.; MAROUELli, W. A.; SILVA, W. L. C. 1-MCP delays tomato fruit ripening. Horticultura Brasileira. Brasília -DF: v.20, n.4, p. 659663, 2002a.

[31] MORETTI, C. L.; COSTA, G. A.; LIMA, A. A.; MAROUELLI, W.; SILVA, W. Qualidade pós-colheita de tomates submetidos a aplicação de 1- metilciclopropeno por diferentes intervalos de tempo. Simiente. Santiago: v. 72 , n. 3-4, jul-dic. 2002 b.
[32] NODA, H. Critérios de avaliação de progênies de irmãos germanos interpopulacionais em berinjela [Solanum melongena L.]. Piracicaba, 1980. 91p. Dissertação [Mestrado em Genética e Melhoramento de Plantas] - ESALQ/USP.

[33] PALIYATH, G.; DROILLARD, M. J. The mechanisms of membrane deterioration and disassembly during senescence. Plant Physiology and Biochemistry, v.30, p. 789-812, 1992.

[34] PAULL, E. R. Effect of temperature and relative humidity on fresh commodity quality. Postharvest Biology and Technology, v.15, p. 263-277, 1999.

[35] PESIS, E.; ACKERMAN, M.; BEN-AIRE, R.; FEYGENBERG, O.; FENG, X.; APELBAUM, A.; GOREN, R.; PRUSKY, D. Ethylene biosynthesis in chilling injury of avocado during cold storage. Postharvest Biology and Technology, v.24, p. 171-181, 2002.

[36] PICCHIONI, G.,A.; VALENZUELA-VAZQUEZ, M.; MURRAY, L. W. Calcium and 1-methylcyclopropene delay desiccation of Lupinus havardii cut racemes. Hortscience, v.37, p. 122-125,2002.

[37] POOVAIAH, B. W.; GLENN, G. M.; REDDY, A. S. N. Calcium and fruit softening: physiology and biochemistry. Horticultural Review, v.10, p. 107-153, 1988.

[38] SALUNKE, D. K.; DESAI, B. B. Postharvest biotechnology of vegetables. Boca Raton: CRC Press, v. 2, 194p. 1984.

[39] SALTVEIT, M. E. Effect of ethylene on quality of fresh fruits and vegetables. Postharvest Biology and Technology, Amsterdam, v.15, p. 279-292,1999.

[40] SILVA, D. J. H.; COSTA, C. P.; CASALI, V. W. D.; DIAS,L. A. S.; CRUZ, C. D. Análise da capacidade combinatória em berinjela. Bragantia, Êv. 58, n.1, 1999.

[41] STOW, J. Effect of calcium ions on apple fruit softening during storage and ripening. Postharvest Biology and Technology, v. 3, p.1-9, 1993.

[42] WARD, G.; NUSSINOVITCH, A. Peel gloss as a potential indicator of banana ripeness. Lebensmitte1Wissenschaft und-Technologie,v. 29, p. 289294,1996. 